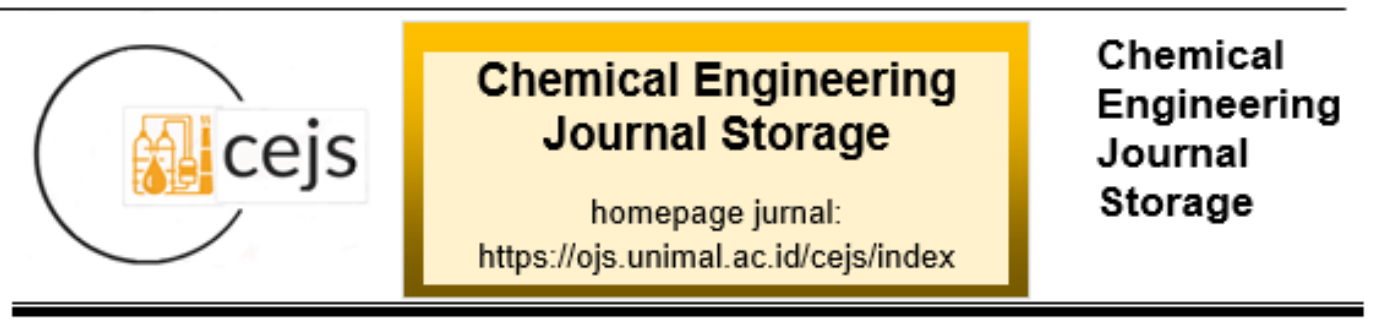

\title{
PENURUNAN KADAR FFA ( FREE FATTY ACID) MENGGUNAKAN ADSORBEN DARI TEMPURUNG KELAPA
}

\author{
Afifa Luthfia ${ }^{1}$, Azhari ${ }^{1}$, Suryati $^{1}$, Sulhatun ${ }^{1}$, Meriatna ${ }^{1}$ \\ ${ }^{1}$ Jurusan Teknik Kimia, Fakultas Teknik, Universitas Malikussaleh \\ Kampus Utama Cot Teungku Nie Reuleut, Muara Batu, Aceh Utara - 24355 \\ Korespondensi:,e-mail: azhari@unimal.ac.id
}

\begin{abstract}
Abstrak
Crude palm oil atau CPO merupakan minyak kelapa sawit mentah yang diperoleh dari hasil ekstraksi atau dari proses pengempaan daging buah kelapa sawit dan belum mengalami pemurnian. Tempurung kelapa memiliki komposisi kimia mirip dengan kayu, yang mengandung lignin, selulosa, dan hemiselulosa. Karbon aktif adalah suatu bahan yang berupa karbon amorf yang mempunyai luas permukaan yang sangat besar yaitu 300 - $2000 \mathrm{~m}^{2} /$ gram. Tujuan dari penelitian adalah mengetahui faktor-faktor pengaruh penurunan FFA (free fatty acid) menggunakan adsorben dari tempurung kelapa dan mengetahui pengaruh dari banyak adsorben yang digunakan dan waktu adsorpsi terhadap penurnan FFA (free fatty acid) pada CPO (crude palm oil). Kandungan FFA (free fatty acid) awal adalah sebesar 16,00\% dan waktu adsorpsi yang digunakan adalah 30, 35, 40, dan 45 menit, pada waktu 30 menit terjadi penuruan asam lemak bebas sebesar 10,25\%, 9,84\% dan 8,97\%. Untuk waktu 35 menit, penurunan asam lemak bebas sesebesar 7,84\%, 7,69\%, dan 7,59\%. Untuk waktu 40 menit, penurunan asam lemak bebas sebesar 7,17\%, 6,92\%, dan 6,56\%. Untuk waktu 45 menit, penurunan asam lemak bebas sebesar 6,20\%, 6\% dan 5,64\%. Variasi berat adsorben yang digunakan adalah 3 gram, 5 gram, dan 7 gram. Pada variasi berat adsorben 3 gram, penyerapan paling maksimal sebesar 6,20\%. Pada variasi berat adsorben 5 gram, penyerapan paling maksimal sebesar 6,00 \%. Pada variasi berat adsorben 7 gram, penyerapan paling maksimal sebesar 5,64 \%. Semakin lama waktu adsorpsi, maka kandungan FFA setelah proses adsorpsi semakin kecil. Makin banyak adsorben yang digunakan maka semakin besar luas permukaan kontak antara adsorben dengan CPO.

Kata kunci: Adsorben, Crude Palm Oil, Free Fatty Acid.
\end{abstract}

\section{Pendahuluan}

Kelapa sawit berasal dari Afrika Barat, nama latinnya adalah Elaeis guineensis yang dari awal mula ditemukan ternyata sudah diketahui mengandung kandungan minyak nabati nan kaya melebihi tanaman lainnya. Masuknya tanaman 
ini pertama kali dibawa oleh pemerintah Hindia Belanda pada 1848. Awal mulanya hanya dibawa empat batang bibit sawit dan kemudian ditanam di Kebun Raya Bogor. Tanaman bibit yang dibawa berasal dari Mauritius (Bourbon) dan Hortus Botanicus, Amsterdam Belanda.

Crude palm oil atau CPO merupakan minyak kelapa sawit mentah yang diperoleh dari hasil ekstraksi atau dari proses pengempaan daging buah kelapa sawit dan belum mengalami pemurnian. Kebutuhan minyak sawit sebesar 90\% digunakan untuk bahan pangan seperti minyak goreng, margarin, shortening, pengganti lemak kakao dan untuk kebutuhan industri roti, cokelat, es krim, biskuit, dan makanan ringan. Kebutuhan $10 \%$ dari minyak sawit lainnya digunakan untuk industri oleokimia yang menghasilkan asam lemak, fatty alcohol, gliserol, dan metil ester serta surfaktan.

Kelapa termasuk jenis Palmae yang bersel satu (monokotil). Buah kelapa umumnya hanya dimanfaatkan untuk kelapa sayur dan minyak goreng. Di beberapa tempat telah berkembang pula berbagai produk olahan dari kelapa dan hasil sampingnya, seperti dessicated coconut, nata de coco, serat sabut, dan arang aktif. Minyak kelapa murni terutama digunakan dalam bidang kesehatan dan kosmetik (Kresnadipayana et al., 2016).

Tempurung kelapa memiliki komposisi kimia mirip dengan kayu, yang mengandung lignin, selulosa, dan hemiselulosa.Tempurung kelapa biasanya digunakan sebagai bahan pokok dalam pembuatan karbon.Hal ini dikarenakan tempurung kelapa merupakan bahan yang dapat menghasilkan nilai kalor sekitar 6500 - $7600 \mathrm{kkal} / \mathrm{kg}$. Selain itu, tempurung kelapa juga cukup baik untuk dijadikan bahan baku dalam pembuatan karbon aktif karena memiliki kadar karbon yang cukup tinggi (Paputungan et al., 2018).

Karbon aktif adalah suatu bahan yang berupa karbon amorf yang mempunyai luas permukaan yang sangat besar yaitu $300-2000 \mathrm{~m}^{2} /$ gram. Luas permukaan yang sangat besar ini disebabkan karena karbon aktif mempunyai struktur pori. Pori-pori inilah yang menyebabkan karbon aktif mempunyai kemampuan untuk menyerap (Dahlan et al., 2013). 
Aktivasi karbon bertujuan untuk memperbesar luas permukaan arang dengan membuka pori-pori yang tertutup tar, hidrokarbon, dan zat-zat organik lainnya, sehingga memperbesar kapasitas adsorpsi. Pada metode pengaktifan secara kimia, arang hasil karbonisasi biasanya direndam dalam larutan aktifasi lalu ditiriskan dan dipanaskan pada suhu tinggi selama 1 - 2 jam. Beberapa bahan kimia yang dapat digunakan sebagai zat pengaktif, antara lain : $\mathrm{H} 3 \mathrm{PO} 4, \mathrm{KOH}$, Na2SO4, ZnCl2, dan Na2CO3 (Pakiding, 2014)

Berdasarkan penelitian yang telat dilakukan, maka peneliti berkesimpulan untuk melakukan penelitian tentang pemanfaatan limbah tempurung kelapa yang digunakan sebagai pembuatan adsorben untuk penurunan kadar asam lemak bebas pada minyak kelapa sawit.

\section{Bahan dan Metode}

Bahan dan peralatan yang diperlukan dalam penelitian ini antara lain adalah tempurung kelapa yang diperoleh dari pasar Krueng Geukuh, $\mathrm{KOH} \mathrm{0,1} \mathrm{N,}$ methanol, $\mathrm{NaOH}$ 0,1 N, Indikator PP dan aquades. Peralatan yang digunakan adalah furnace, oven, buret dan lain-lain.

Penelitian ini terdiri dari tahap persiapan tempurung kelapa menjadi adsorben. Variasi percobaan dilakukan terhadap waktu adsorpsi dengan variasi yakni 30 menit, 35 menit, 40 menit dan 45 menit. Variasi percobaan juga dilakukan terhadap jumlah adsorben yang digunakan.

Pembuatan adsorben tempurung kelapa dimulai dengan pembakaran tempurung kelapa hingga menjadi arang dengan furnace, lalu di haluskan menggunakan blender dan di ayak menggunakan ayakan dengan ukuran 80 mesh. Kemudian dilanjutkan dengan proses aktivasi menggunakan senyawa kimia, pada penelitian ini menggunakan $\mathrm{KOH}$, lalu dinetralkan menggunakan aquades dan di keringkan menggunakan oven hingga menjadi serbuk. Penurunan kadar Free fatty acid dapat diketahui dengan melakukan pengujian menggunakan metode titrasi.

Kemudian dilanjutkan dengan melakukan analisa isotherm adsorpsi, yakni isotherm Langmuir dan isotherm Freundlich. Isoterm freundlich menggambarkan adsorpsi jenis fisika dimana adsorpsi terjadi pada beberapa lapis dan ikatannya 
tidak kuat. Cara konvensional untuk menyatakan isoterm freundlich diberikan persamaan sebagai berikut, (Lempang, 2014)

$Q e=K_{\mathrm{f}} C e^{1 / \mathrm{n}}$

Konstanta freundlich menunjukkan ikatan antara adsorbat dengan adsorben dan diperoleh dengan cara eksperimen. Untuk mendapatkan konstanta $K_{\mathrm{f}} . C e^{1 / \mathrm{n}}$, maka perlu dilakukan linerisasi terhadap persamaan sebagai berikut: $\operatorname{Ln}(\mathrm{Qe})=\ln K f+1 / \mathrm{n} \ln \mathrm{Ce}$ dimana,

$$
\begin{aligned}
& \mathrm{Qe}=\text { jumlah adsorbat pada permukaan }(\mathrm{mg} / \mathrm{g}) \\
& \mathrm{Ce}=\text { konsentrasi equilibrium }(\mathrm{mg} / \mathrm{l}) \\
& K f \text { dan } \mathrm{n}=\text { konstanta }
\end{aligned}
$$

Dari data percobaan laboratorium yang diperoleh diplot dengan ln (Qe) sebagai sumbu y dan $\ln \mathrm{C}$ sebagai sumbu x. Grafik yang diperoleh adalah garis linear dengan slope $=1 / \mathrm{n}$ dan intercept $=\ln K f($ Wijayanti \& Kurniawati, 2019).

Isoterm langmuir mendefinisikan bahwa kapasitas adsorben maksimum terjadi akibat adanya lapisan tunggal (monolayer) adsorbat pada permukaan adsorben. Dalam bentuk yang umum, persamaan isoterm langmuir adalah sebagai berikut (Irvan et al., 2016)

$$
\frac{c_{e}}{q_{e}}=\frac{1}{q_{e}} c_{e}+\frac{1}{K_{L} \cdot q_{m}}
$$

Dimana:

$$
\begin{aligned}
& \mathrm{Ce}=\text { konsentrasi equilibrium }(\mathrm{mg} / \mathrm{l}) \\
& \mathrm{Qe}=\text { adsorbat yang terserap pada saat equilibrium }(\mathrm{mg} / \mathrm{g}) \\
& \mathrm{KL}=\text { konstanta Langmuir }(1 / \mathrm{mg}) \\
& \mathrm{Qm}=\text { kapasitas adsorpsi }
\end{aligned}
$$

Pada grafik isotherm langmuir dengan 1/Qe sebagai sumbu y dan $1 / \mathrm{Ce}$ sebagai sumbu $\mathrm{x}$ akan diperoleh persamaan garis $(\mathrm{y}=\mathrm{bx}+\mathrm{a})$ yang akan menentukan nilai $\mathrm{Qm}$ dan $\mathrm{KL}$, dimana $\mathrm{Qm}$ adalah 1/a sedangkan $\mathrm{KL}$ adalah nilai b 


\section{Hasil dan Diskusi}

\subsection{Pengaruh Waktu Adsorpsi terhadap Kadar FFA Setelah Adsorpsi.}

Setelah dilakukan proses adsorpsi menggunakan adsorben dari tempurung kelapa maka Suhu dan FFA yang dihasilkan dapat dilihat pada Gambar 1.

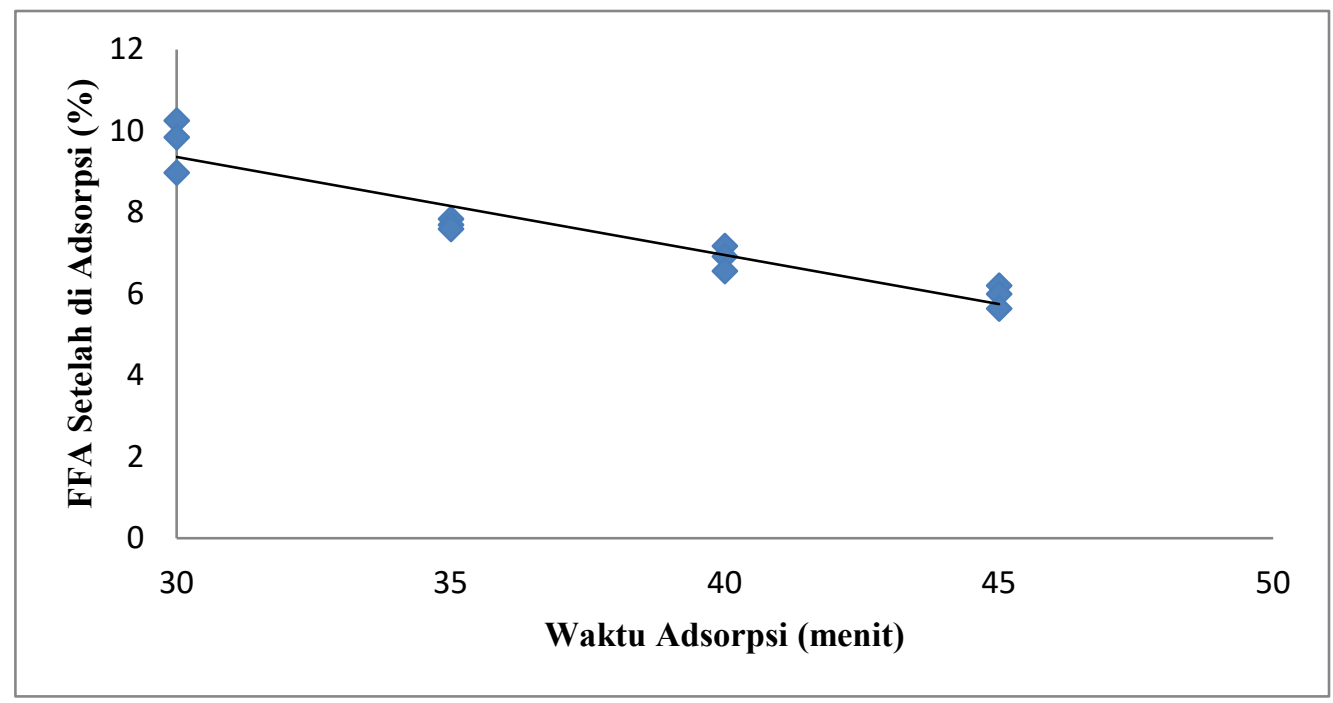

Gambar 2. Pengaruh waktu adsorpsi terhadap penuruna kadar FFA setelah proses adsorpsi menggunakan adsorben dari tempurung kelapa

Adanya waktu adsorpsi ini menyebabkan proses adsorpsi berjalan optimal. Waktu adsorpsi yang digunakan adalah 30, 35, 40, dan 45 menit, pada waktu 30 menit terjadi penuruan asam lemak bebas sebesar 10,25\%, 9,84\% dan 8,97\%. Untuk waktu 35 menit, penurunan asam lemak bebas sesebesar 7,84\%, 7,69\%, dan 7,59\%. Untuk waktu 40 menit, penurunan asam lemak bebas sebesar 7,17\%, $6,92 \%$, dan 6,56\%. Untuk waktu 45 menit, penurunan asam lemak bebas sebesar 6,20\%,6\% dan 5,64\%. Dari keempat waktu tersebut dapat dilihat, bahwa waktu penurunan asam lemak bebas yang bagus terjadi pada 45 menit. Pada dasarnya semakin lama waktu adsorpsi dan pengadukan, maka kandungan FFA setelah proses adsorpsi semakin kecil. Waktu kontak yang cukup diperlukan untuk mencapai kesetimbangan adsorpsi. Jika fase cair yang berisi adsorben dalam keadaan diam, maka difusi adsorbat melalui permukaan adsorben akan lambat, maka diperlukan pengadukan untuk mempercepat adsorpsi. (Sulistyo et al., 2016) 


\subsection{Pengaruh Banyak Adsorben terhadap Kadar FFA Setelah Adsorpsi.}

Setelah dilakukan proses adsorpsi FFA menggunakan adsorben dari tempurung kelapa maka pengaruh banyak adsorben pada saat adsorpsi terhadap FFA setelah adsorpsi dapat dilihat pada Gambar 2.

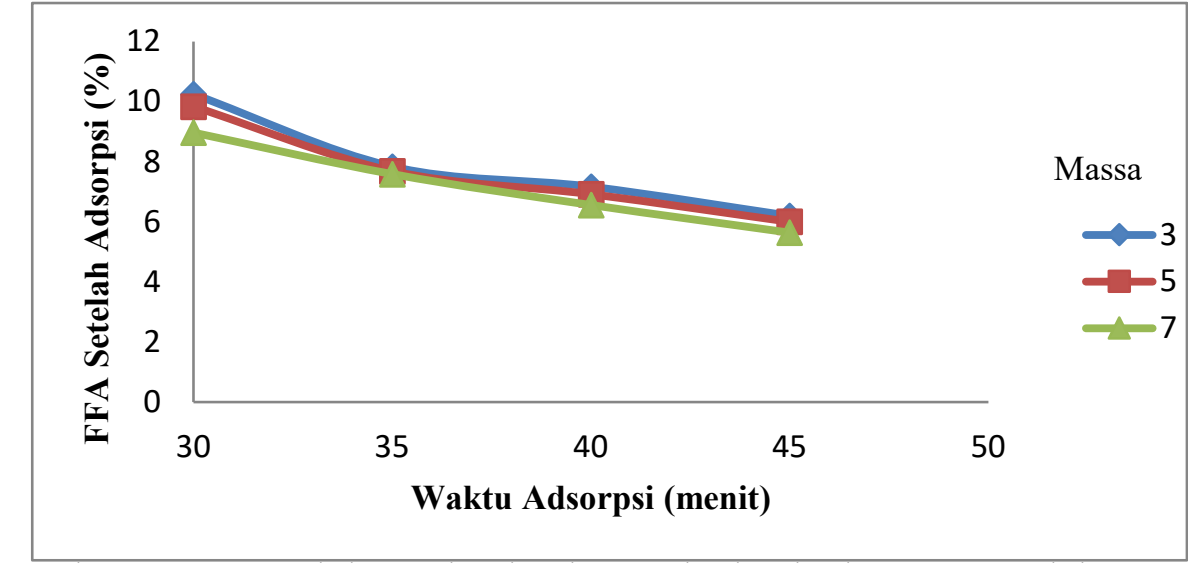

Gambar 2. Pengaruh banyak adsorben terhadap kadar FFA setelah proses adsorpsi dengan menggunakan adsorben dari tempurung kelapa.

Variasi berat adsorben yang digunakan adalah 3 gram, 5 gram, dan 7 gram. Pada berat 3 gram, penyerapan paling maksimal sebesar 9,8\%. Pada berat 5 gram, penyerapan paling maksimal sebesar $10 \%$. Pada berat 7 gram, penyerapan paling maksimal sebesar 10,36 \%. Penyerapan FFA (free fatty acid) paling bagus ketika adsorben yang digunakan sebanyak 7 gram. Hal ini disebabkan karena, makin banyak adsorben yang digunakan maka akan makin besar atau banyak luas pemukaan yang menyerap asam lemak bebas pada CPO. Besarnya ukuran dan pori-pori adsorben mempengaruhi luas permukaannya. Semakin kecil ukuran adsorben maka luas permukaan akan semakin besar. Semakin besar pori-pori adsorben maka semakin besar pula luas permukaan adsorben. Pori-pori dapat diperbesar dengan aktivasi (Idrus et al., 2013).

\subsection{Isoterm Adsorpsi}

Isothermal Adsorpsi merupakan proses penyerapan zat terlarut oleh padatan suhu dan tekanan konstan. Pada isotherm terlihat jumlah zat terserap yang dipengaruhi oleh konsentrasi keseimbangannya dan digunakan untuk karakteristik dari persamaan antara jumlah adsorbat yang terakumulasi dalam adsorben dan konsentrasi larutan adsorbat. 
Analisa Isoterm Adsorpsi merupakan hubungan kesetimbangan antara jumlah adsorbat yang diserap oleh adsorben sebagai fungsi konsentrasi dan suhu atau kesetimbangan antara konsentrasi adsorbat dalam fluida dan pada permukaan adsorben pada suhu yang tetap. Ada beberapa tipe isotherm yang sering digunakan untuk mengetahui mekanisme adsorpsi FFA oleh tempurung kelapa yang diaktivasi. Tipe Isotherm Adsorpsi yang umumnya dianut oleh adsorpsi padat-cair yaitu tipe Isoterm Freundlich dan Langmuir. Pada Isoterm Langmuir dilakukan dengan cara membuat kurva $\mathrm{Q}_{\mathrm{e}} / \mathrm{C}_{\mathrm{e}}$ terhadap $\mathrm{C}_{\mathrm{e}}$, sedangkan untuk Isoterm Freundlich dilakukan dengan cara membuat kurva hubungan log Qe terhadap $\log \mathrm{Ce}$.

Grafik Isotherm Adsorpsi FFA menggunakan adsorben dari tempurung kelapa dapat dilihat masing-masing pada pada Gambar 3 dan 4.

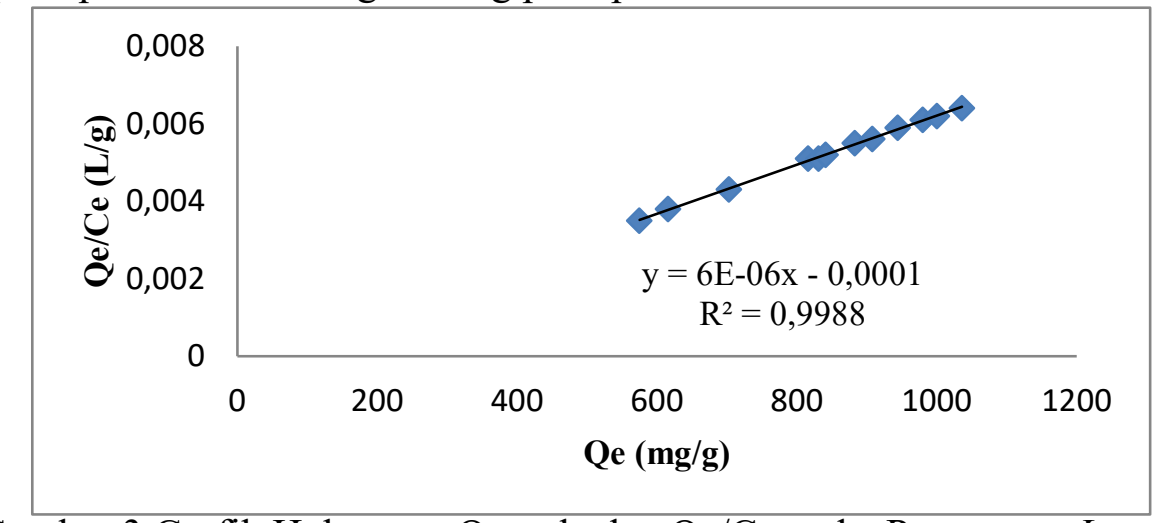

Gambar 3 Grafik Hubungan Qe terhadap Qe/Ce pada Persamaan Langmuir

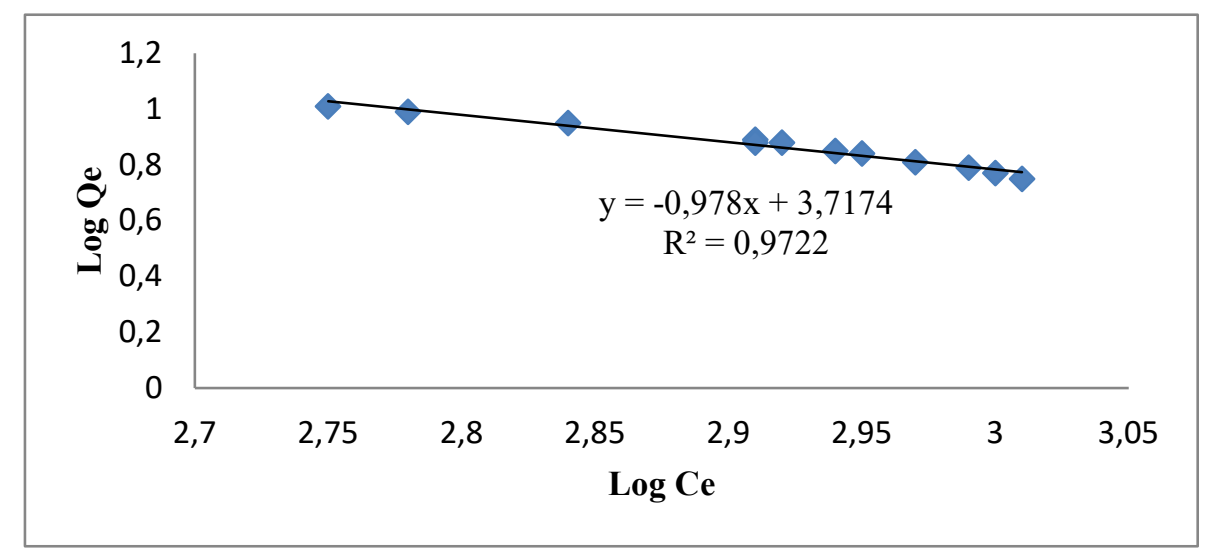

Gambar 4 Grafik Hubungan Log Ce terhadap Log Qe pada Persamaan Freundlich 
Dari Gambar 4.4 dan 4.5 dapat dilihat bahwa pengujian persamaan Langmuir dan Freundlich memiliki liniarisasi yang berbeda. Untuk persamaan Langmuir memiliki harga $\mathrm{R}^{2}$ yaitu 0.9988 dan untuk persamaan freundlich memiliki harga $\mathrm{R}^{2}$ sebesar 0.9722 . Linearisasi isotherm langmuir didapat nilai slope dan intersept dari persamaan $\mathrm{Y}=0,000006$ - 0.0001 dengan menggunakan pers. (2.2) dimana $b$ adalah konstanta isoterm langmuir $(\mathrm{L} / \mathrm{mg})$, sedangkan $\mathrm{Q}_{\mathrm{e}}$ adalah kapasitas penyerapan maksimum monolayer $(\mathrm{mg} / \mathrm{g})$. Nilai slope dan intersept untuk linearirasi persamaan freundlich didapat hasil $\mathrm{y}=-0.978+3.7174$ dengan mengggunakan pers.(2.4).

Besaran harga $\mathrm{R}^{2}$ menandakan bahwa persamaan Langmuir lebih cocok diterapkan pada proses adsorpsi FFA menggunakan adsorben dari tempurung kelapa dari pasar Krueng Geukuh, Aceh Utara. Isoterm Langmuir menggambarkan kesesuaian antara data eksperimen dengan model lebih sesuai dibandingkan dengan model freundlich. Nilai koefisien korelasi yang diperoleh 0,9988 yang artinya bahwa penelitian model penyerapan yang terjadi adalah monolayer (akibat adanya lapisan tunggal).

Nilai parameter dari regresi linear persamaan Langmuir dan freundlich dapat dilihat pada Tabel 1

Tabel 1 Parameter isorterm Langmuir dan Freundlich

\begin{tabular}{|c|l|c|c|c|}
\hline \multirow{2}{*}{$\begin{array}{c}\text { Equilibrium } \\
\text { Adsorpsi }\end{array}$} & \multicolumn{1}{|c|}{ Persamaan linear } & \multicolumn{2}{|c|}{ Konstanta } & \multirow{2}{*}{$\mathbf{R}^{\mathbf{2}}$} \\
\hline \multirow{2}{*}{ Langmuir } & $\frac{q e}{C e}=0,000006-0.0001 \mathrm{qe}$ & $\mathrm{Qm}$ & $166.666,666$ & \multirow{2}{*}{0.9988} \\
\cline { 3 - 4 } & & $\mathrm{K}_{\mathrm{L}}-0,0600000002$ & \\
\hline \multirow{2}{*}{ Freundlich } & $\begin{array}{l}\text { Log Qe }=0,3333 \mathrm{x}+1,3333 \\
\operatorname{logCe}\end{array}$ & $\mathrm{Kf}$ & 1,12492 & \multirow{2}{*}{0.9722} \\
\cline { 3 - 4 } & & $1 / \mathrm{n}$ & 0,3333 & \\
\cline { 3 - 5 } & & $\mathrm{n}$ & 0,3333 & \\
\hline
\end{tabular}

\section{Simpulan dan Saran}

Pada waktu kontak selama 45 menit kadar FFA turun menjadi 6,20\%, 6\% dan 5,64\% yang dimana FFA awalnya adalah $16 \%$.Semakin lama waktu adsorpsi dan pengadukan, maka kandungan FFA setelah proses adsorpsi semakin kecil. Waktu 
kontak yang cukup diperlukan untuk mencapai kesetimbangan adsorpsi. Makin banyak adsorben yang digunakan maka akan makin besar atau makin luas permukaan kontak yang menyerap asam lemak bebas pada CPO. Besarnya ukuran dan pori-pori adsorben mempengaruhi luas permukaannya. Semakin kecil ukuran adsorben maka luas permukaan akan semakin besar. Penelitian ini lebih mengarah pada model isoterm Langmuir, dapat dilihat dari koefisien korelasi $\left(\mathrm{R}^{2}\right)$ yakni 0,9988. Jika nilai kofisien korelasi mendekati 1 maka dinyatakan sempurna.

Penelitian ini dapat dilanjutkan dengan mengganti aktivator yang digunakan seperti HCL dan melakukan variasai suhu adsorpsi yang digunakan agar mengetahui suhu yang maksimal untuk penelitian ini. Penambahan uji karakteristik adsorben juga dapat ditambahkan pada penelitian selanjutnya agar mengetahui karakteristik dari adsorben tempurung kelapa.

\section{Daftar Pustaka}

1. Dahlan, M. H., Siregar, H. P., \& Yusra, M. (2013). Dapat Memurnikan Minyak Jelantah. Jurnal Teknik Kimia, 19(3), 44-53.

2. Idrus, R., Lapanporo, B. P., \& Putra, Y. S. (2013). Pengaruh Suhu Aktivasi Terhadap Kualitas Karbon Aktif Berbahan Dasar Tempurung Kelapa. Prisma Fisika, I(1), 50-55.

3. Irvan, Olyvia Putri Wardhani, Nurul Aini, \& Iriany. (2016). Adsorpsi BKaroten Yang Terkandung Dalam Minyak Kelapa Sawit (Crude Palm Oil) Menggunakan Karbon Aktif. Jurnal Teknik Kimia USU, 5(1), 52-57.

4. Kresnadipayana, D., Pratiwi, R., \& Primadevi, S. (2016). Biosorpsi Cu ( II ) oleh Limbah Padat Kayu Aren (Arenga pinnata) Teraktivasi. Biomedika, 9(1), 43-48.

5. Lempang, M. (2014). Pembuatan dan Kegunaan Karbon Aktif. Info Teknis EBONI, 11(2), 65-80.

6. Pakiding, L. M., Sumarni, N. K., \& Musafira. (2014). Aktivasi Arang Tempurung Kelapa dengan $\mathrm{ZnCl} 2$ dan Aplikasinya dalam Pengolahan Minyak Jelantah. Online Journal of Natural Science , 47-54Paputungan, R., Nikmatin, S., Maddu, A., \& Pari, G. (2018). Mikrostruktur Arang Aktif Batok Kelapa Untuk Pemurnian Minyak Goreng Habis Pakai. Jurnal Keteknikan Pertanian, 6(1), 71-76. 
7. Paputungan, R., Nikmatin, S., Maddu, A., \& Pari, G. (2018). Mikrostruktur Arang Aktif Batok Kelapa untuk Pemurnian Minyak Goreng Habis Pakai. Jurnal Keteknikan Pertanian, 69-74.

8. Sulistyo, R., Lestari, D., Sari, D. K., Rosmadiana, A., \& Dwipermata, B (2016). Aplikasinya Pada Pemurnian Minyak Goreng Bekas. Jurnal Teknika , 419-430

9. Wijayanti, I. E., \& Kurniawati, E. A. (2019). Studi Kinetika Adsorpsi Isoterm Persamaan Langmuir dan Freundlich pada Abu Gosok sebagai Adsorben. EduChemia (Jurnal Kimia Dan Pendidikan), 4(2), 176-1849 